\title{
Mechanism of Calcium Fluoride Acceleration for Vacuum Carbothermic Reduction of Magnesia
}

\begin{abstract}
YUN JIANG, YU-QIN LIU, HONG-WEN MA, and WEI-GONG ZHOU
The use of a small amount of calcium fluoride as an additive greatly accelerated the reduction of magnesia during the preparation of magnesium from magnesia using the vacuum carbothermic reduction method. At $1573 \mathrm{~K}\left(1300{ }^{\circ} \mathrm{C}\right)$, the magnesia reaction rates of the samples with 1,3 , and 5 pct $\mathrm{CaF}_{2}$ were all approximately 26 pct, three times that of free $\mathrm{CaF}_{2}$, and they were arranged in order of the calcium fluoride weight percentages at $1673 \mathrm{~K}\left(1400{ }^{\circ} \mathrm{C}\right)$. The residues were analyzed using chemical analysis, XRD, SEM, EDS, and XRF. The possible acceleration mechanism was discussed. Calcium fluoride combined with magnesia and silicon dioxide to form a eutectic that melted as a channel to aid the solid-solid reaction between carbon and magnesia at approximately $1573 \mathrm{~K}\left(1300{ }^{\circ} \mathrm{C}\right)$. Calcium fluoride in the molten state offered free calcium ions and fluorine ions. Fluorine ions entered and distorted the magnesia crystal lattice. The structural strength and chemical stability of the magnesia crystal lattice decreased, which facilitated the magnesia reduction by carbon. Calcium ions were employed to generate the calcium and magnesium silicate. The easyly evaporating fluorides, including magnesium fluoride and silicon tetrafluoride, were regarded as the main reason for the loss of fluorine.
\end{abstract}

DOI: $10.1007 / \mathrm{s} 11663-015-0531-7$

(C) The Author(s) 2015. This article is published with open access at Springerlink.com

\section{INTRODUCTION}

CAlcium fluoride has been widely used as a reaction accelerator in ferroalloy production and ferrous metallurgy, including magnesium metallurgy. ${ }^{[1-8]}$ During the industrial production of magnesium using the Pidgeon process in China, calcium fluoride may be added at a nominal rate of $0.2 \mathrm{~kg}$ per $1 \mathrm{~kg}$ of pure magnesium. ${ }^{[9]}$ Calcium fluoride also obviously enhances the reaction rate of magnesia in the preparation of magnesium using vacuum carbothermic reduction method.

Based on the previous thermodynamic analysis, the carbothermic reduction reaction is

$$
\mathrm{MgO}_{(\mathrm{s})}+\mathrm{C}_{(\mathrm{s})}=\mathrm{Mg}_{(\mathrm{g})}+\mathrm{CO}_{(\mathrm{g})} .
$$

The reaction between magnesia and carbon produces magnesium vapor and carbon monoxide. The gaseous mixture is cooled down when it is pulled out from the heating system. The magnesium vapor condenses on the surface of the condenser, and carbon monoxide is expelled from the equipment. The system pressure affects the reaction because solid materials transform

YUN JIANG, Lecturer, is with the School of Science, China University of Geosciences, 29 Xueyuan Road, Haidian District, Beijing 100083, China. YU-QIN LIU, Associate Professor, and HONG-WEN MA, Professor, are with the School of Materials Science and Technology, China University of Geosciences, 29 Xueyuan Road, Haidian District, Beijing 100083, China. Contact e-mail: mahw@cugb.edu.cn WEI-GONG ZHOU, Associate Professor, is with the Great Wall College, China University of Geosciences, 1698 South Second Ring Road, Baoding 071000, China.

Manuscript submitted July 21, 2015.

Article published online December 14, 2015. into gaseous products during the reaction. The decrease of the system pressure contributes to the forward reaction. The thermodynamic calculation indicates that the beginning reaction temperature dips to $1387 \mathrm{~K}$ $\left(1114^{\circ} \mathrm{C}\right)$ when the system pressure in the vacuum oven is $20 \mathrm{~Pa}{ }^{[10]}$

Some experiments on the vacuum carbothermic reduction of magnesia with various amounts of calcium fluoride have been performed. $\mathrm{Li}^{[11]}$ noted that the rapid reaction temperature without $\mathrm{CaF}_{2}$ is approximately $1750 \mathrm{~K}\left(1477^{\circ} \mathrm{C}\right)$ at $150 \mathrm{~Pa}$. Tian ${ }^{[12]}$ confirmed that the reaction with 5 pct $\mathrm{CaF}_{2}$ at 30 to $100 \mathrm{~Pa}$ is sharply accelerated only at $1573 \mathrm{~K}\left(1300^{\circ} \mathrm{C}\right)$. $\mathrm{Gao}^{[13]}$ observed that the magnesia reaction rate with 5 pct $\mathrm{CaF}_{2}$ at $1673 \mathrm{~K}\left(1400{ }^{\circ} \mathrm{C}\right)$ for an hour increased from 31.02 to 91.72 pct. However, the mechanism of calcium fluoride in the experiment is not fully clear and remains worthy of investigation. Therefore, experiments and analyses have been conducted to investigate the effect and mechanism of calcium fluoride on the reaction.

\section{EXPERIMENTS}

A series of experiments were performed. The raw materials were magnesia, coke, and calcium fluoride. Light magnesium oxide and calcium fluoride, produced by the Sinopharm Chemical Reagent Co., Ltd., were both analytical reagent with nominal purities of 98.0 and 98.5 pct, respectively. Senior grade metallurgical coke with some complex components produced in Shanxi, China, was used as the reductant. The chemical compositions of magnesia, coke, and calcium fluoride are listed in Tables I, II, and III, respectively. 
Table I. Chemical Composition Analysis Results of Light Magnesium Oxide ( $\left.w_{\mathrm{B}} / \mathrm{pct}\right)$

\begin{tabular}{lccccccc}
\hline Item & $\mathrm{SiO}_{2}$ & $\mathrm{Al}_{2} \mathrm{O}_{3}$ & $\mathrm{Fe}_{2} \mathrm{O}_{3}$ & $\mathrm{TiO}_{2}$ & $\mathrm{CaO}$ & $\mathrm{MgO}$ & 0.02 \\
\hline Content & 0.06 & 0.03 & 0.01 & 0.02 & $\mathrm{~K}_{2} \mathrm{O}$ \\
\hline Item & $\mathrm{Na}_{2} \mathrm{O}$ & $\mathrm{MnO}$ & $\mathrm{SO}_{3}$ & $\mathrm{P}_{2} \mathrm{O}_{5}$ & $\mathrm{H}_{2} \mathrm{O}-$ & 0.01 \\
\hline Content & 0.06 & 0.00 & 0.02 & 0.00 & 0.00 & Loss of Ignition \\
\hline
\end{tabular}

Table II. Chemical Composition Analysis Results of Coke ( $\left.w_{\mathrm{B}} / \mathrm{pct}\right)$

\begin{tabular}{|c|c|c|c|c|c|c|c|}
\hline Item & M, ad & A, ad & $\mathrm{V}$, ad & $\mathrm{FC}$, ad & $\mathrm{FC}, \mathrm{d}$ & \multicolumn{2}{|c|}{ Coke Cinder Character } \\
\hline Content & 0.22 & 14.74 & 1.46 & 83.58 & 83.67 & \multicolumn{2}{|c|}{2} \\
\hline Item & $\mathrm{SiO}_{2}$ & & & $\mathrm{Fe}_{2} \mathrm{O}_{3}$ & $\mathrm{TiO}_{2}$ & $\mathrm{CaO}$ & $\mathrm{MgO}$ \\
\hline Content & 45.40 & & & 10.57 & 1.62 & 3.44 & 0.75 \\
\hline Item & $\mathrm{K}_{2} \mathrm{O}$ & & & $\mathrm{MnO}$ & $\mathrm{SO}_{3}$ & $\mathrm{P}_{2}$ & \\
\hline Content & 0.80 & & & 0.19 & 2.05 & 0.2 & \\
\hline
\end{tabular}

Note: 'M,ad' is the total moisture content of the raw coke sample, 'A,ad' is the ash content, 'V,ad' is the volatile content, 'FC,ad' is the fixed carbon content, and 'FC,d' is the fixed carbon content of the dried coke sample. 'Coke cinder character' describes the residues' shape and property after the determination of volatiles, and the coke cinder characteristic code ' 2 ' indicates that it was adhesive and the larger mass more easily became a powder with gentle touch. The items after $\mathrm{SiO}_{2}$ (including $\mathrm{SiO}_{2}$ ) represent the chemical composition analysis of ash $(\mathrm{A}, \mathrm{ad})$.

Table III. Chemical Composition Analysis Results of Calcium Fluoride ( $\left.w_{\mathrm{B}} / \mathrm{pct}\right)$

\begin{tabular}{lccccc}
\hline Item & $\mathrm{CaF}_{2}$ & Loss of Ignition & Chloride & Sulfite & Total Nitrogen \\
\hline Content & $\geq 98.5$ & $\leq 0.4$ & $\leq 0.01$ & $\leq 0.05$ & $\leq 0.005$ \\
\hline Item & Fluorosilicate & Phosphate & Fe & Heavy Metal \\
\hline Content & $\leq 0.01$ & qualified & $\leq 0.003$ & $\leq 0.003$
\end{tabular}

Note: Because of the difficulty in the $\mathrm{CaF}_{2}$ analysis, the data in the table are the nominal values.

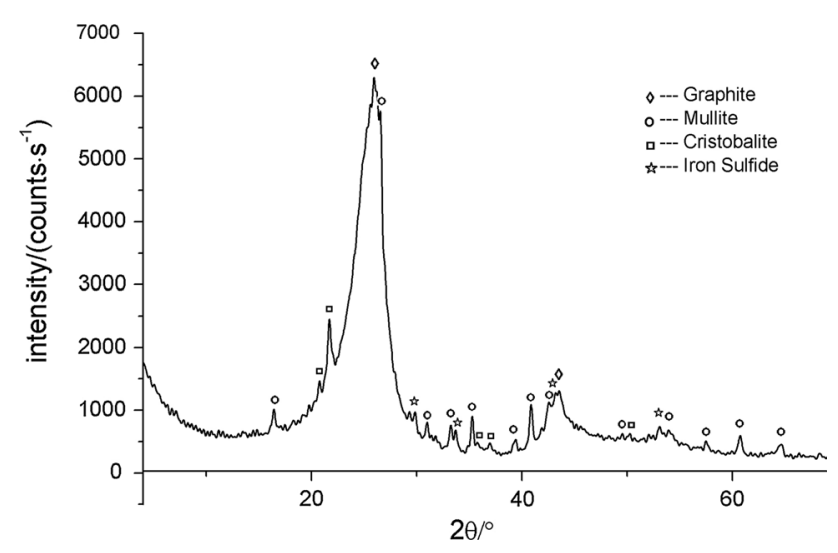

Fig. 1-XRD pattern of coke.

The X-ray diffraction (XRD) analysis result of coke is shown in Figure 1. The fixed carbon in the sample was 83.58 pct and remained in the phase of amorphous carbon and graphite crystallite, appearing as a raised bulge corresponding to the graphite peak. The main ingredients in its ash were silica and alumina, which existed as the mullite phase $\left(\mathrm{Al}_{6} \mathrm{Si}_{2} \mathrm{O}_{13}\right)$ and cristobalite phase $\left(\mathrm{SiO}_{2}\right)$.

To ensure calcium fluoride's impact on the reducing process, a group of contrast experiments were conducted. The coke and light magnesium oxide were mixed evenly based on the molar ratio of carbon and magnesia (1.2). The mass percentages of silica and alumina in the total mixture were 2.20 and 1.61 pct, respectively. Other substances, including iron oxide, made up less than 0.52 pct and had little effect; thus they were not considered. The powder was divided in quarters; 1, 3, and 5 wt pet $\mathrm{CaF}_{2}$ was added to three of the quarters, and the remaining quarter was left free of $\mathrm{CaF}_{2}$. The four parts were separately ground, mixed evenly again, and pressured into pellets with diameters of $40 \mathrm{~mm}$ using a pressure of $20 \mathrm{MPa}$. The four types of pellets were named RS0, RS1, RS3, and RS5 according to the addition of calcium fluoride.

The shaped samples were placed into a vacuum oven. The oven was closed, and a vacuum pump was used to reduce the system pressure. Heating began until the system pressure 
reached $5 \mathrm{~Pa}$. The first series of experiments examined the effect of temperature. The reactions lasted 60 minutes at $1373 \mathrm{~K}, 1473 \mathrm{~K}, 1573 \mathrm{~K}$, and $1673 \mathrm{~K}\left(1100{ }^{\circ} \mathrm{C}, 1200{ }^{\circ} \mathrm{C}\right.$, $1300{ }^{\circ} \mathrm{C}$, and $1400{ }^{\circ} \mathrm{C}$ ). Another series of experiments examined the effect of reaction time. The reactions occurred in $1673 \mathrm{~K}\left(1400^{\circ} \mathrm{C}\right)$ for $0,30,60$, and 90 minutes. The system pressure rose to approximately $20 \mathrm{~Pa}$ during the heating stage and ranged stably from 20 to $8 \mathrm{~Pa}$ when the temperature was maintained at a certain level. All of the residues were analyzed using the chemical method, and some of them were examined using X-ray diffraction (XRD), X-ray fluorescence (XRF), and scanning electron microscopy (SEM).

\section{ANALYSIS AND RESULTS}

The raw sample kept its pellet shape but shrank successively during the reaction. When the sample did not fully reacted, the residue has an ash layer with the radius of $R_{\mathrm{O}}$ outside after the gas product left and an unreacted hard core inside with the radius of $R_{\mathrm{I}}$. With time lasting or temperature rising, the sample became completely dark gray porous fragile ash bulk, in which there was still less carbon and magnesia. During the process, the radius was becoming smaller from the raw sample's $R_{\mathrm{S}}$ to the ash bulk's $R_{\mathrm{A}}$. Figure 2 shows the reaction process.

\section{A. Reaction Rate of Magnesia}

The reaction rate of magnesia is calculated using the following formula:

$\beta=\frac{W_{0}-W_{1}}{W_{0}} \times 100 \mathrm{pct}=\frac{\alpha_{0} \times m_{0}-\alpha_{1} \times m_{1}}{\alpha_{0} \times m_{0}} \times 100 \mathrm{pct}$,

where $W_{0}$ is the magnesia mass before reduction, which is obtained using the formula $W_{0}=\alpha_{0} \times m_{0}$, in which $\alpha_{0}$ is the weight percent of magnesia and $m_{0}$ is the total mass of the reactants. $W_{1}, \alpha_{1}$, and $m_{1}$ correspond to the mass of magnesia, the weight percent of magnesia, and the total mass of the residue after the reduction, respectively.

Figure 3 shows the relation between the reaction rate and weight percentage of $\mathrm{CaF}_{2}$. In Figure 3(a), the reaction rates were almost the same at 5 pct at $1373 \mathrm{~K}$ $\left(1100{ }^{\circ} \mathrm{C}\right)$ or lower, indicating that the reduction reaction between coke and magnesia did not occur. At $1473 \mathrm{~K}\left(1200{ }^{\circ} \mathrm{C}\right)$, the reaction rates changed slightly. At $1573 \mathrm{~K}\left(1300{ }^{\circ} \mathrm{C}\right)$, the reaction rates of the reactants with $\mathrm{CaF}_{2}$ were similar $(25.20,27.00$, and $26.81 \mathrm{pct}$ ) regardless of the weight percentages of calcium fluoride. It was three times that of free $\mathrm{CaF}_{2}(9.52 \mathrm{pct})$. At 1673 $\mathrm{K}\left(1400{ }^{\circ} \mathrm{C}\right)$, the reaction rates were arranged in order of weight percentage of $\mathrm{CaF}_{2}$ at 43.70, 52.51, and 61.60 pct. Their reaction rates were approximately double that without $\mathrm{CaF}_{2}$ (26.14 pct).

In Figure 3(b), the reaction rates of magnesia at 1673 $\mathrm{K}\left(1400{ }^{\circ} \mathrm{C}\right)$ were arranged in order of weight percentage of $\mathrm{CaF}_{2}$ for a reaction time of 90 minutes. These values were obviously higher than that of RS0. The reaction rates of $\mathrm{RS} 0$ increased linearly with time, whereas those of the samples containing $\mathrm{CaF}_{2}$ slowed down with the same trend when the reaction time lasted more than 30 minutes because at 30 minutes, the gap between RS1 and RS0, RS3 and RS0, and RS5 and RS0 were maintained at approximately 16, 25, and $33 \mathrm{pct}$, respectively, with no obvious change. The difference occurs when the reaction temperature increases from $1573 \mathrm{~K}$ to $1673 \mathrm{~K}\left(1300{ }^{\circ} \mathrm{C}\right.$ to $\left.1400{ }^{\circ} \mathrm{C}\right)$ and when the time is less than 30 minutes.

\section{B. X-ray Diffraction Analysis}

The comparison group's residues were analyzed to identify the phase transition in each stage of the reaction. The XRD spectrum of the raw samples and residues are shown in Figure 4. The raw samples, RS0, RS1, RS3, and RS5, were named based on the addition of calcium fluoride. The residues were named according to the experiment conditions and the addition of calcium fluoride. For example, the code 1473603 indicates that the residue came from the sample with 3 wt pct $\mathrm{CaF}_{2}$ that had reacted at $1473 \mathrm{~K}\left(1200{ }^{\circ} \mathrm{C}\right)$ for 60 minutes (the first four numbers are the reacting temperature, the next two are the reacting time, and the last one is the weight percentage of $\mathrm{CaF}_{2}$ in the sample).

In Figure 4, mullite $\left(\mathrm{Al}_{6} \mathrm{Si}_{2} \mathrm{O}_{13}\right)$ and cristobalite $\left(\mathrm{SiO}_{2}\right)$ always disappeared, and the spinel $\left(\mathrm{MgAl}_{2} \mathrm{O}_{4}\right)$ and olivine $\left(\mathrm{Mg}_{2} \mathrm{SiO}_{4}\right)$ appeared after the samples were heated at $1473 \mathrm{~K}\left(1200{ }^{\circ} \mathrm{C}\right)$ for 60 minutes.

For the samples containing $\mathrm{CaF}_{2}$, the calcium fluoride peaks increased with the weight percentage of $\mathrm{CaF}_{2}$. When the reaction temperature increased, the calcium
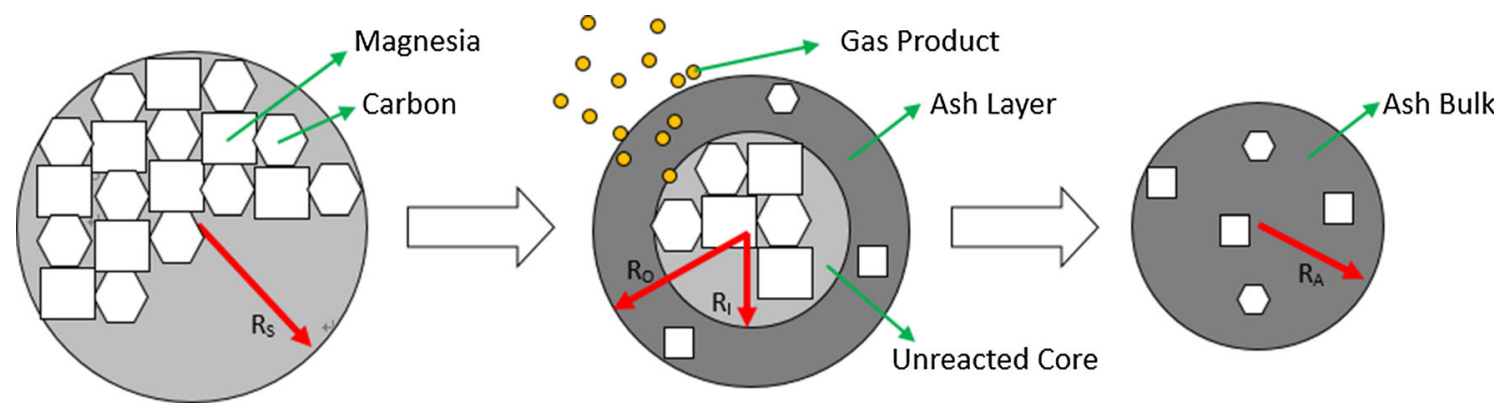

Fig. 2-Status of raw sample and residue. 


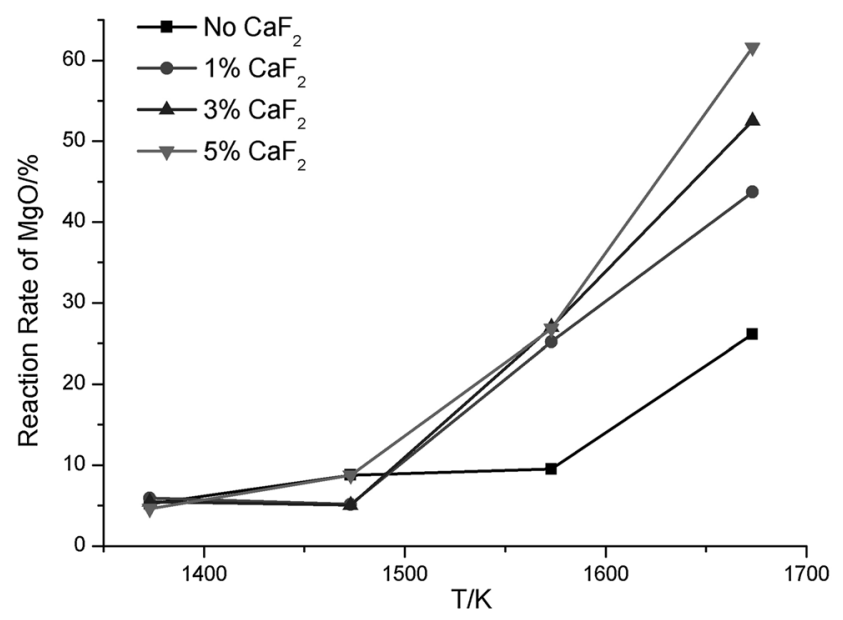

(a)

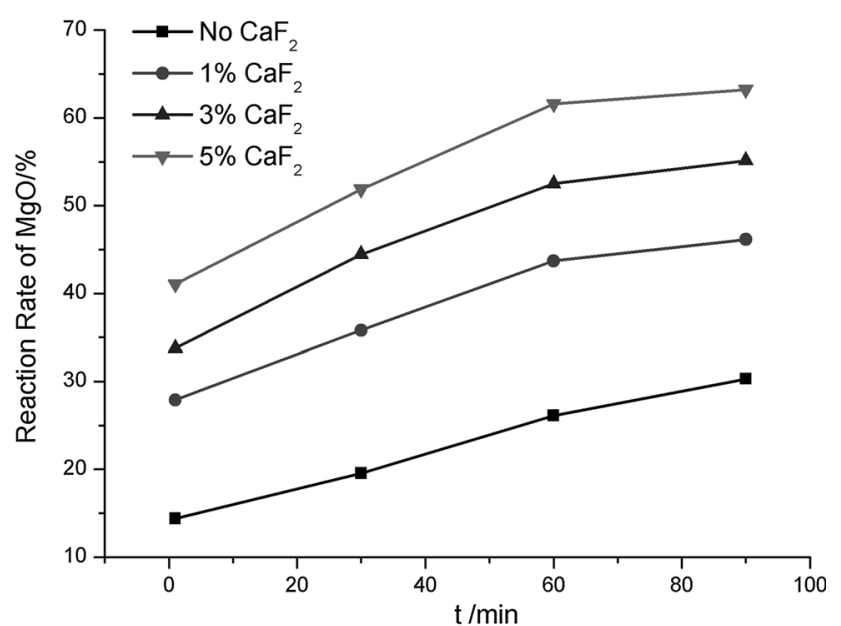

(b)

Fig. 3-Magnesia reaction rate change as a function of weight percentage of $\mathrm{CaF}_{2}$. (a) Effect of temperature $(60 \mathrm{~min})$ and $(b)$ effect of time $\left[1673 \mathrm{~K}\left(1400{ }^{\circ} \mathrm{C}\right)\right]$.

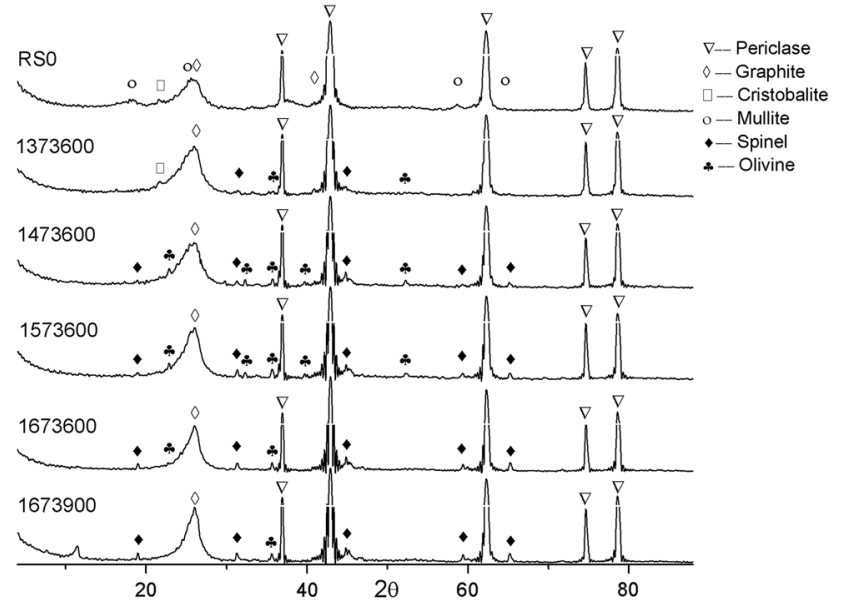

(a)

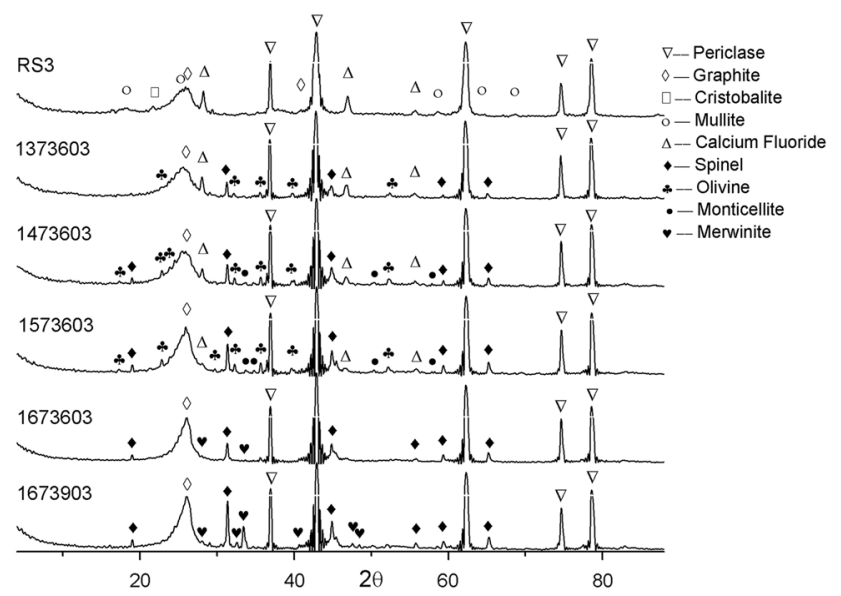

(c)

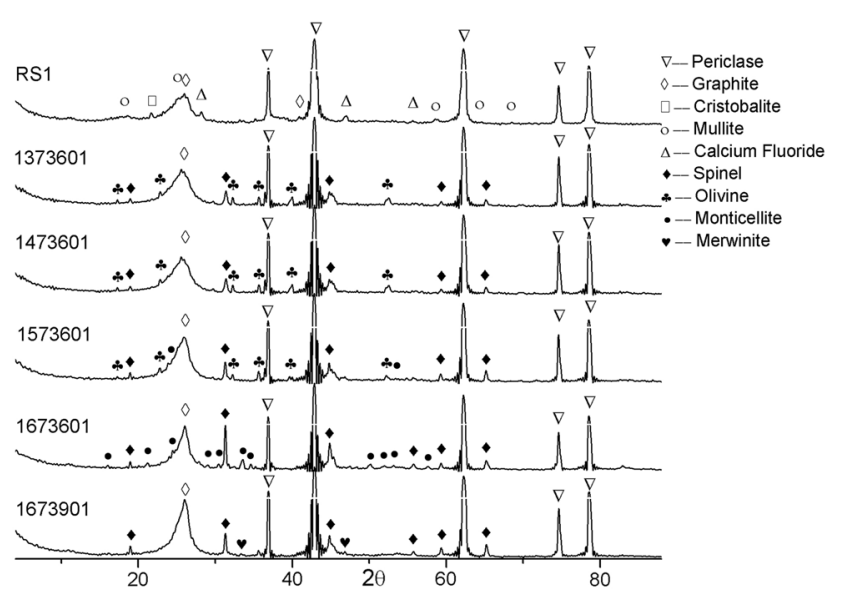

(b)

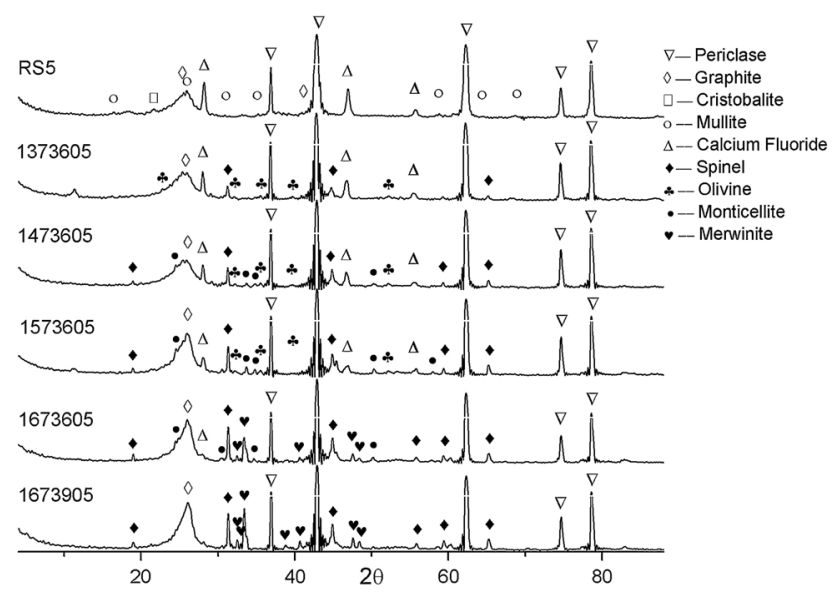

(d)

Fig. 4-XRD patterns of raw samples and residues under various experiment conditions. (a) RS0 and its residue, (b) RS1 and its residue, $(c)$ RS3 and its residue, and (d) RS5 and its residue. 
fluoride peaks generally decreased and eventually vanished. When less calcium fluoride was added, the peaks disappeared more quickly.

The olivine phase $\left(\mathrm{Mg}_{2} \mathrm{SiO}_{4}\right)$ appeared at $1373 \mathrm{~K}$ $\left(1100{ }^{\circ} \mathrm{C}\right)$ in all of the samples. For sample RS0, the olivine phase was present at every reaction temperature. For RS1, RS3, and RS5, the olivine phase was present from $1373 \mathrm{~K}$ to $1573 \mathrm{~K}\left(1100{ }^{\circ} \mathrm{C}\right.$ to $\left.1300{ }^{\circ} \mathrm{C}\right)$ and was then replaced by other phases containing calcium.

The monticellite phase $\left(\mathrm{CaMgSiO}_{4}\right)$ did not appear until $1573 \mathrm{~K}\left(1300{ }^{\circ} \mathrm{C}\right)$ for sample RS1, reached a high level when the sample was heated at $1673 \mathrm{~K}\left(1400{ }^{\circ} \mathrm{C}\right)$ for 60 minutes, and then disappeared after 90 minutes. For samples RS3 and RS5, the phase appeared at $1473 \mathrm{~K}\left(1200{ }^{\circ} \mathrm{C}\right)$ and reached its highest level at $1573 \mathrm{~K}\left(1300{ }^{\circ} \mathrm{C}\right)$. The phase vanished in RS3 and was still present in RS5 when the temperature reached $1673 \mathrm{~K}\left(1400{ }^{\circ} \mathrm{C}\right)$. The addition amount of $\mathrm{CaF}_{2}$ determined the duration that the monticellite phase remained in the samples.

The merwinite phase $\left(\mathrm{Ca}_{3} \mathrm{Mg}\left(\mathrm{SiO}_{4}\right)_{2}\right)$ appeared at $1673 \mathrm{~K}\left(1400{ }^{\circ} \mathrm{C}\right)$ for 90 minutes for RS1 and at same temperature for 60 minutes for RS3 and RS5. For a higher $\mathrm{CaF}_{2}$ weight percentage, the merwinite phase appeared earlier.

\section{X-ray Fluorescence Analysis}

Several elements, including calcium, silicon, fluorine, and aluminum, were the second main elements except the carbon and magnesium for the raw samples. The residues of RS3 were ground and analyzed using the X-ray fluorescence method. The weight loss percentages of the elements were calculated and are shown in Figure 5. The loss of fluorine increased progressively with an increase in the reaction temperature. A loss of 92.4 pct fluorine occurred at $1673 \mathrm{~K}\left(1400{ }^{\circ} \mathrm{C}\right)$ after 60 minutes, and the fluorine vanished after 90 minutes. The weight of the other three elements changed less when the reaction temperature was below $1573 \mathrm{~K}$ $\left(1300{ }^{\circ} \mathrm{C}\right)$; however, their loss almost doubled at $1673 \mathrm{~K}\left(1400{ }^{\circ} \mathrm{C}\right)$, especially that of silicon $(57.7 \mathrm{pct})$.

\section{Scanning Electron Microscope and Energy Spectrum Analysis}

The SEM images in Figure 6 show the surface details of the samples. Figure 6(a) shows the sample before the reaction, in which the large gray bulk represents the unbroken coke with a relatively neat edge, whereas the white fine particles are a mixture of the magnesia and a small account of calcium fluoride. Figure 6(b) shows the residue after the reaction at $1473 \mathrm{~K}\left(1200{ }^{\circ} \mathrm{C}\right)$ for 60 minutes. The coke edge is still neat. The mixture combined more tightly than before. Figure 6(c) shows the residue after the reaction at $1573 \mathrm{~K}\left(1300{ }^{\circ} \mathrm{C}\right)$ for 60 minutes. The gray flakes are coke with a coarse surface and toothed edge. The magnesia grew into larger spherical particles, approximately $1 \mu \mathrm{m}$, combined together, and some caves appeared. The cross-linker in the middle is thought to be a type of silicate based on its crystal shape. The phenomenon indicated that the

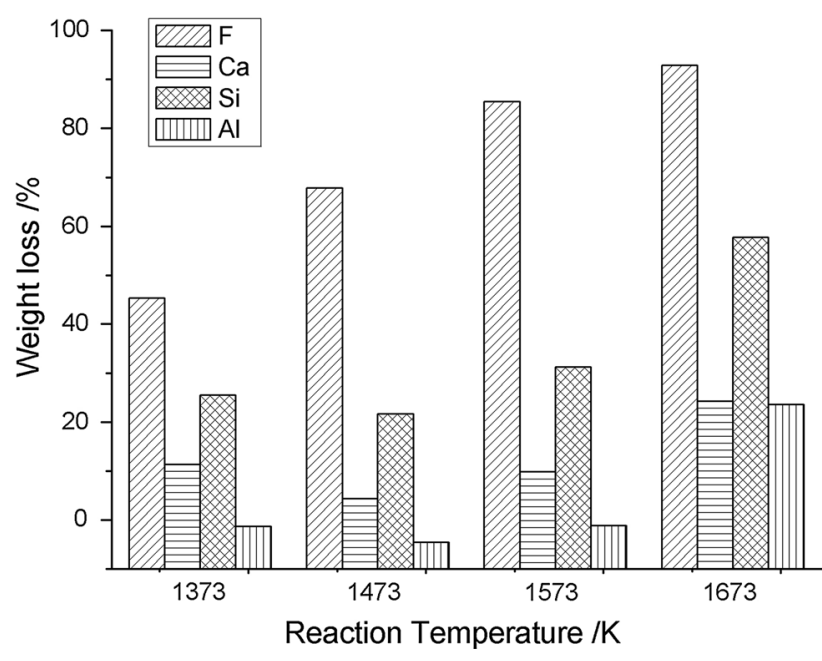

Fig. 5-Weight loss percentage of elements in RS3 at various reaction temperatures.

materials began to react fast at $1573 \mathrm{~K}\left(1300{ }^{\circ} \mathrm{C}\right)$. Figure 6(d) shows how the spherical particle's size continued to grow to approximately $3 \mu \mathrm{m}$ and blurred the grain boundary. The scattered debris is the ash of coke. The cave increased in size because of the consumption of reactants.

The cemented parts in residues 1473603 and 1573603 were probed by EDS. Figure 7 shows the probed area, and Table IV lists the micro-area atomic percentage. The cemented part of 1473603 contained seven elements, including $\mathrm{C}, \mathrm{Mg}, \mathrm{O}, \mathrm{Ca}, \mathrm{F}, \mathrm{Si}$, and $\mathrm{Al}$, and the magnesium and oxygen contents were 40.36 and 46.74 pct, respectively. Fluorine and calcium still coexisted in 1473603 even if their atomic proportion was 1.72 , which is higher than that of calcium fluoride, 0.5 . In the cemented part of 1573603 , the magnesium and oxygen contents dipped to 14.81 and 9.35 pct, respectively. The calcium atomic percent reached $26.25 \mathrm{pct}$; however, the fluorine atomic percent, with silicon and aluminum, became zero.

\section{DISCUSSION}

The experiments demonstrated that calcium fluoride plays an important role in the vacuum carbothermic reduction of magnesia. Comparison of the reaction rates of magnesia with different amounts of calcium fluoride, shown in Figure 3, suggests that the $\mathrm{CaF}_{2}$ does not lower the initial temperature of reduction [1387 K $\left(1114{ }^{\circ} \mathrm{C}\right)$ theoretically]. Only when the reaction begins, the acceleration of calcium fluoride makes the reaction rates distinct.

According to the above experimental results, RS1, RS3, and RS5 have similar reaction rates at $1573 \mathrm{~K}$ $\left(1300{ }^{\circ} \mathrm{C}\right)$ after 60 minutes and have the same reaction rate growth at $1673 \mathrm{~K}\left(1400{ }^{\circ} \mathrm{C}\right)$ when the time is longer than 30 minutes. The amount of $\mathrm{CaF}_{2}$ shows its effect when the temperature ranges from $1573 \mathrm{~K}$ to $1673 \mathrm{~K}$ $\left(1300{ }^{\circ} \mathrm{C}\right.$ to $\left.1400{ }^{\circ} \mathrm{C}\right)$. Higher weight percentages of $\mathrm{CaF}_{2}$ result in higher reaction speeds. Therefore, the 


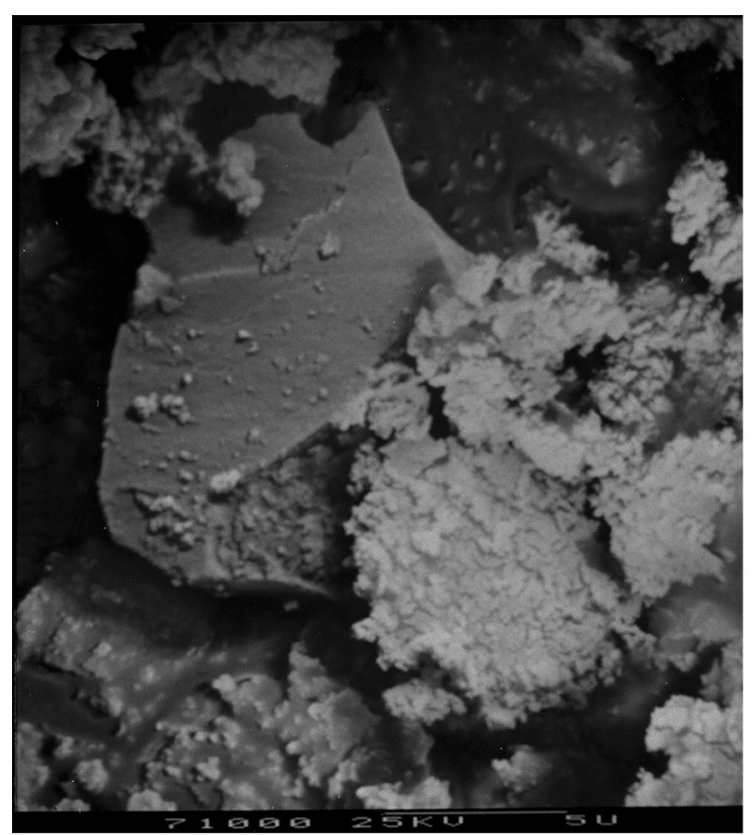

(a)

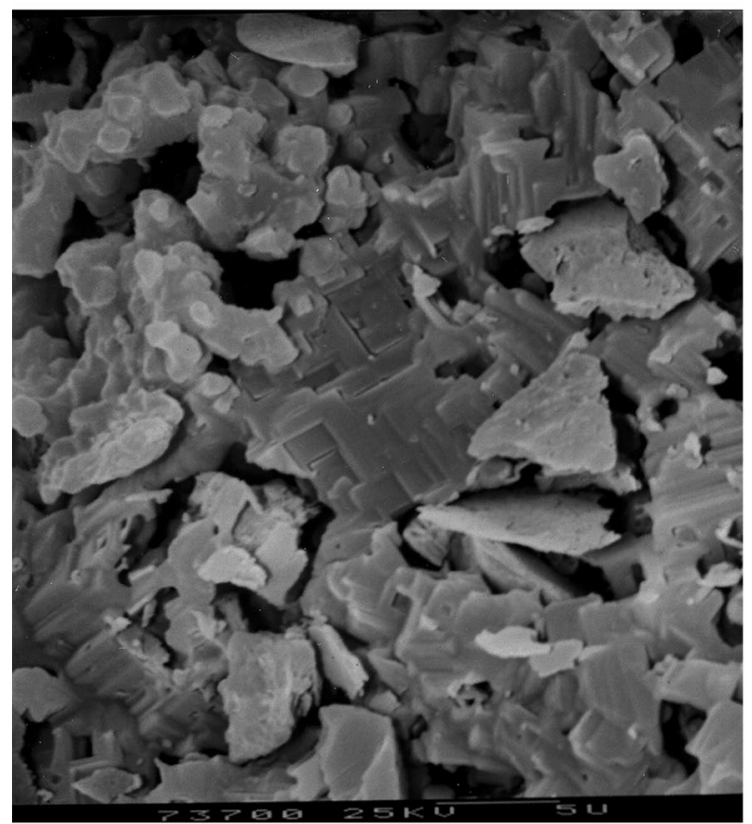

(c)

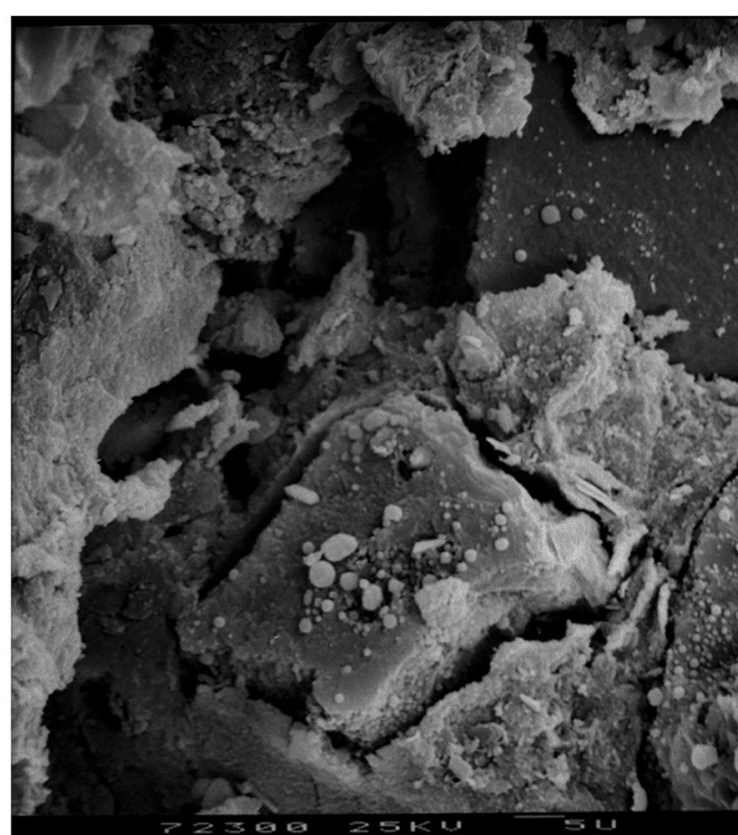

(b)

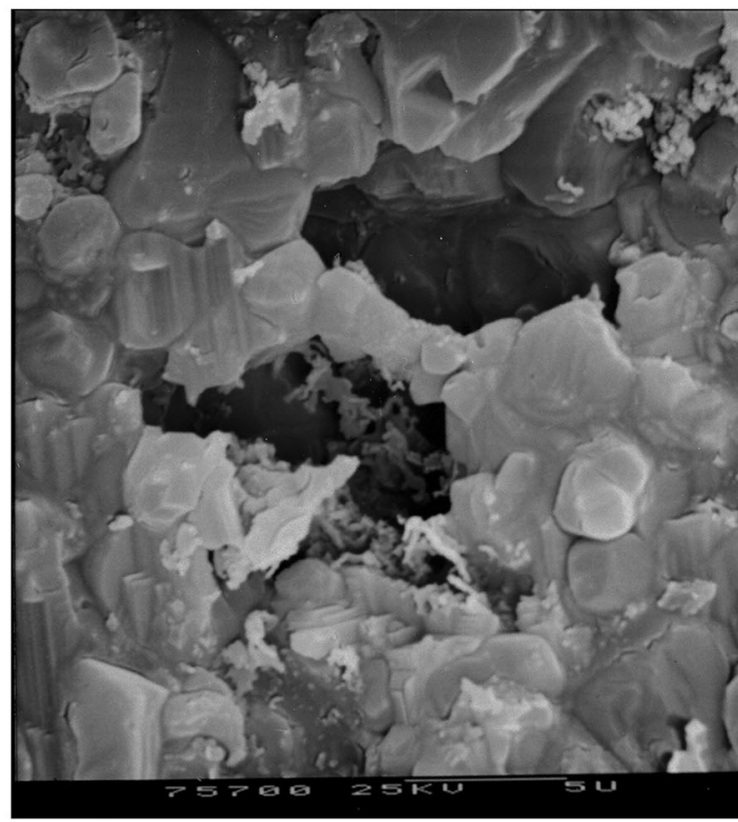

(d)

Fig. 6-SEM images of RS3 and its residues after 60 min. (a) RS3, (b) 1473603, (c) 1573603, and (d) 1673603.

calcium fluoride behavior in that interval should be examined. The analysis results indicate that the acceleration of calcium fluoride can be explained by two mechanisms. One is the formation of the eutectic, and the other is the role of calcium and fluorine ions.

\section{A. Kinetics}

The raw samples are typically carbon-containing pellets, mainly made of magnesia and carbon. The reaction process of carbon-containing pellets is always described by the unreacted shrinking core model, and the status of vacuum carbothermic reaction of magnesia, in Figure 2, is consistent with the unreacted shrinking core model, so the model is used for data fitting. ${ }^{[14,15]}$ In the model, for spherical particles, the relationship between the time and reaction rate is given depending on the rate-limiting step: chemical reaction, diffusion through the product layer, or combination of reaction and diffusion.

When the first-order chemical reaction function, $f(\beta)=(1-\beta)^{\frac{2}{3}}-1$, is plotted against time, a linear fit indicates that chemical reaction is the controlling step. In Figure 8, the plots from bottom to top have, respectively, the regression coefficients of 0.9754 , 

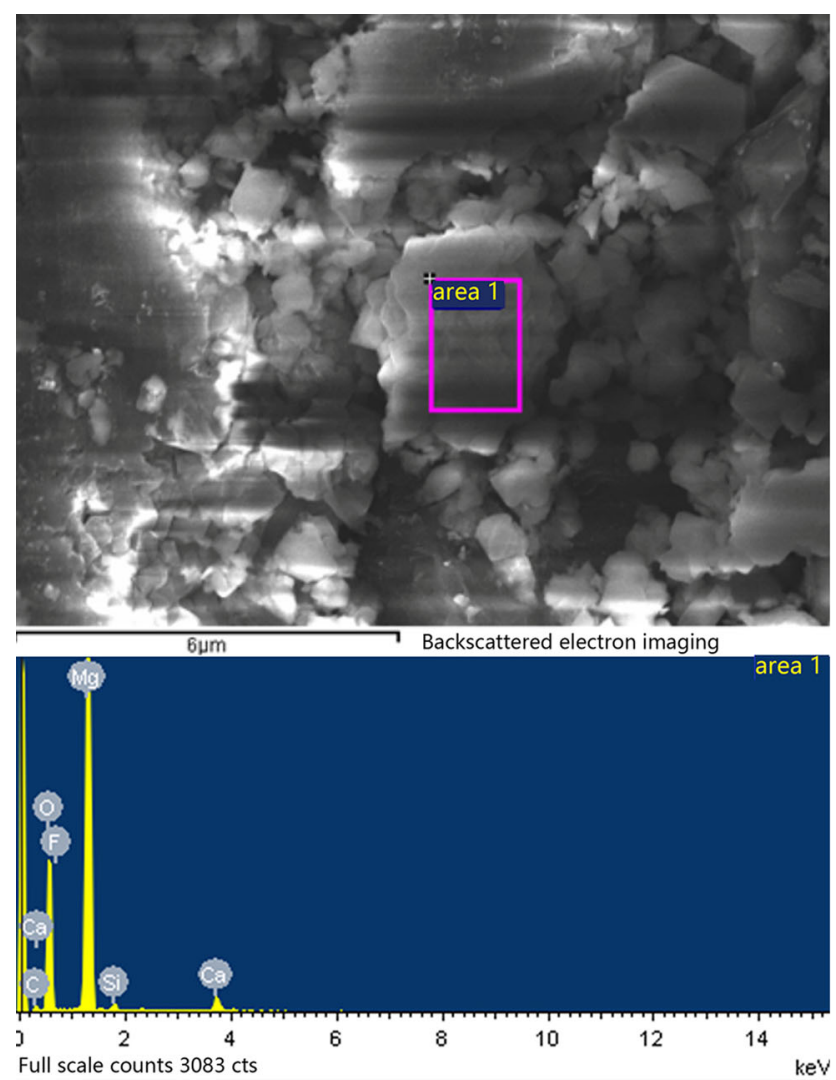

(a)
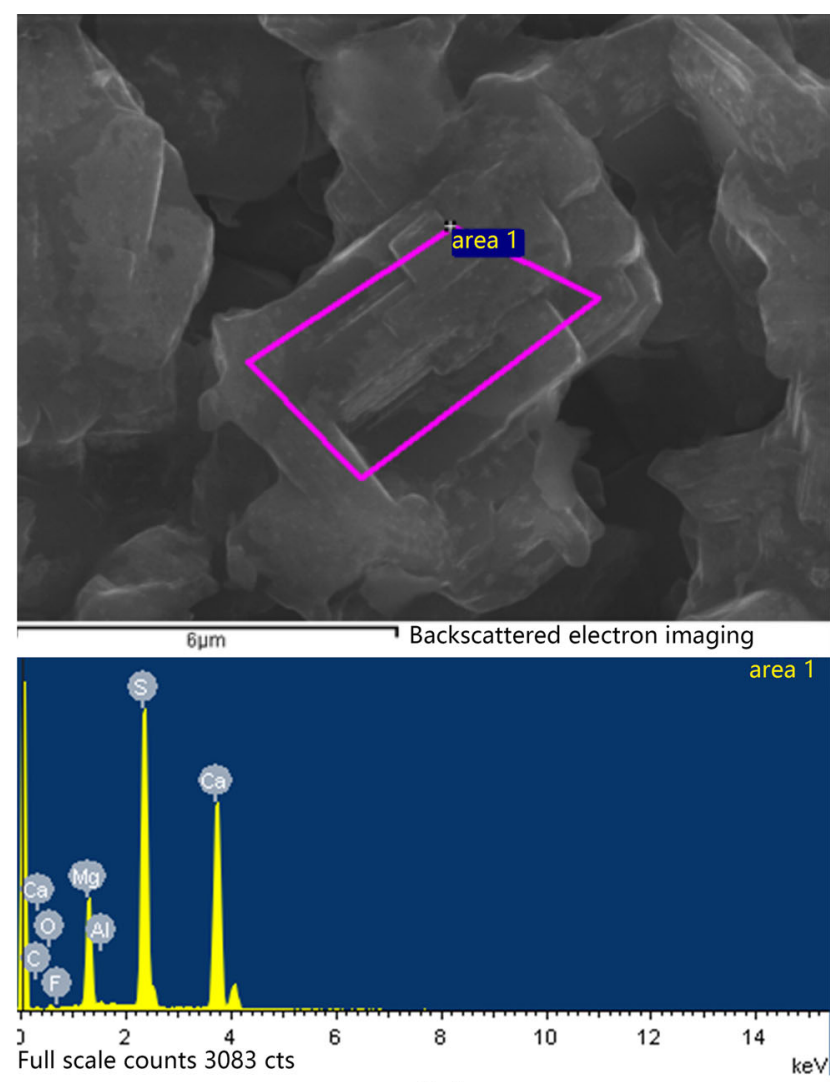

(b)

Fig. 7-Detected areas in the electron images and elemental analysis spectra. (a) 1473603 and (b) 1573603.

Table IV. Element Content Analysis of the Marked Macro-Area

\begin{tabular}{lcrrrrrrrr}
\hline Reaction Condition $\left[\mathrm{K}\left({ }^{\circ} \mathrm{C}\right)\right]$ & Element & $\mathrm{C}$ & $\mathrm{Mg}$ & $\mathrm{O}$ & $\mathrm{Ca}$ & $\mathrm{F}$ & $\mathrm{Si}$ & $\mathrm{Al}$ & $\mathrm{S}$ \\
\hline $1473(1200)$ & at. pct/pct & 9.75 & 40.36 & 46.74 & 1.58 & 0.92 & 0.65 & 0.48 & 0.00 \\
$1573(1300)$ & at. pct/pct & 19.33 & 14.81 & 9.35 & 26.15 & 0.00 & 0.00 & 0.00 & 29.89 \\
\hline
\end{tabular}

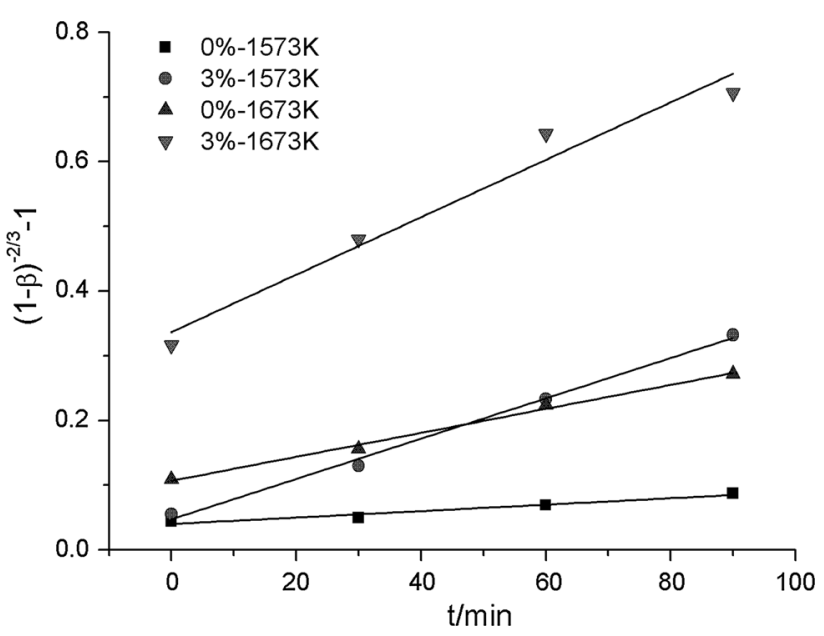

Fig. 8 - Curve of $f(\beta)=(1-\beta)^{\frac{2}{3}}-1$ against time.
0.9961, 0.9967, and 0.9704. The plot for the sample with 3 pet $\mathrm{CaF}_{2}$ at $1673 \mathrm{~K}\left(1400{ }^{\circ} \mathrm{C}\right)$ inflects after 60 minutes probably because the $\mathrm{CaF}_{2}$ has been consumed by 92.82 pct, shown in Figure 5. The chemical reaction rate constant, $\mathrm{k}$, is estimated from the linear plots, 0.499, $1.86,3.12$, and $4.45\left(* 10^{-3}\right)$, respectively.

Arrhenius equation is $k=A e^{\frac{E_{\mathrm{a}}}{R T}}$, where $k$ is the reaction rate constant, $R$ is the molar gas constant, $A$ is the pre-exponential factor, and $E_{\mathrm{a}}$ is the apparent activation energy, the minimum energy for a reaction. $E_{\mathrm{a}}$ is $190.9 \mathrm{~kJ} / \mathrm{mol}$ for the reaction with 3 pet $\mathrm{CaF}_{2}$ and $401.0 \mathrm{~kJ} / \mathrm{mol}$ for that without $\mathrm{CaF}_{2}$. It is obvious that the calcium fluoride decreases the apparent activation energy of carbothermal reduction of magnesia and enhances the reaction speed.

\section{B. Formation of the Eutectic}

The thermodynamic calculation and XRD patterns also indicate that mullite decomposed and formed spinel 
and olivine at $1473 \mathrm{~K}\left(1200{ }^{\circ} \mathrm{C}\right)$, as demonstrated in the following chemical equation:

$$
\mathrm{Al}_{6} \mathrm{Si}_{2} \mathrm{O}_{13}+3 \mathrm{MgO}=3 \mathrm{MgAl}_{2} \mathrm{O}_{4}+2 \mathrm{SiO}_{2},
$$

$$
2 \mathrm{MgO}+\mathrm{SiO}_{2}=\mathrm{Mg}_{2} \mathrm{SiO}_{4} .
$$

Of course, the original cristobalite in the coke also reacts as in Eq. [4].

Berezhnoi ${ }^{[16]}$ studied the phase diagram of $\mathrm{MgO}-\mathrm{SiO}_{2}-$ $\mathrm{CaF}_{2}$ and pointed out that the olivine phase $\left(\mathrm{Mg}_{2} \mathrm{SiO}_{4}\right)$ and calcium fluoride $\left(\mathrm{CaF}_{2}\right)$ have eutectic temperatures lower than $1473 \mathrm{~K}\left(1200{ }^{\circ} \mathrm{C}\right)$ when their molar ratio is approximately 1 , which is close to their molar ratio in RS3 $\left(\mathrm{SiO}_{2}: \mathrm{CaF}_{2}=1.08\right)$. The olivine phase and calcium fluoride likely generate eutectics in the molten state when the reaction temperature is approximately $1473 \mathrm{~K}$ $\left(1200^{\circ} \mathrm{C}\right)$. SEM (Figure 6(c)) and EDS (Figure 7(a)) analyses also indicate that the eutectics were generated. The eutectics in the molten state provide access to this solid-solid reaction process between carbon and magnesia, which was identified in a previous study. ${ }^{[10]}$

\section{Role of Fluorine and Calcium Ions}

Calcium fluoride does promote the magnesia reduction by coke, and the two phenomena demonstrate that calcium and fluorine ions work separately. First, for the XRD patterns (Figure 4), $\mathrm{CaF}_{2}$ decreases with increasing temperature for RS1, RS3, and RS5; some silicate phases containing calcium appear, whereas other phases containing fluorine ions do not appear. Second, the EDS (Figure 7) spectra indicate that both calcium and fluorine were present in the eutectic at $1473 \mathrm{~K}\left(1200{ }^{\circ} \mathrm{C}\right)$; however, only calcium was present at $1573 \mathrm{~K}\left(1300{ }^{\circ} \mathrm{C}\right)$.

Calcium fluoride is a type of ionic compound, and the ionic bond easily breaks in the molten state. ${ }^{[17]}$ Therefore, it could be regarded that the calcium ions and fluorine ions are free in the molten eutectic system at temperatures above $1473 \mathrm{~K}\left(1200{ }^{\circ} \mathrm{C}\right)$.

On one hand, the role of fluorine ions is discussed. Fluorine ions and oxygen ions have similar ionic radii of 0.133 and $0.140 \mathrm{~nm}$, respectively, which means that the $\mathrm{F}^{-}$ easily replaced the position of $\mathrm{O}^{2-}$ in the magnesia crystal lattice. ${ }^{[18]}$ In addition, $\mathrm{F}^{-}$is a monovalent ion and $\mathrm{O}^{2-}$ is a divalent ion. Two $\mathrm{F}^{-}$are needed to satisfy the potential to maintain magnesia's electric neutrality. Mirhadi ${ }^{[19]}$ believed that two $\mathrm{Si}-\mathrm{F}$ bands could replace one $\mathrm{Si}-\mathrm{O}-\mathrm{Si}$ band, which contributed to the breakage of the silica network and the reduction of the stability of the glass structure due to the similarity of ionic radii of fluorine and oxygen. The equilibria are described using the following equations:

$$
\begin{aligned}
& 2 \mathrm{MgO}+2 \mathrm{~F}^{-}=2 \mathrm{MgF}^{-}+\mathrm{O}_{2} \\
& \mathrm{MgO}+2 \mathrm{~F}^{-}=2 \mathrm{MgF}_{2}+\mathrm{O}^{2-} .
\end{aligned}
$$

The crystal lattice would be distorted and lead to the decrease of its structural strength and chemical stability; then carbon would easily reduce the unstable magnesia. ${ }^{[20-22]}$
Sheline ${ }^{[23]}$ confirmed that the molten magnesium fluoride facilitates the decomposition of magnesia by investigating the electrolytic production of $\mathrm{Mg}$ from $\mathrm{MgO}$ both experimentally and theoretically. Wang ${ }^{[24]}$ provided experimental evidence that magnesium fluoride is generated during the reduction of magnesia with 3 wt pet $\mathrm{CaF}_{2}$. A small addition of ash in the crystallizer near the reaction area was analyzed by $\mathrm{XRD}$, in which the main component was $\mathrm{MgF}_{2}$ (60 to $70 \mathrm{wt}$ pct) with small amounts of $\mathrm{CaF}_{2}$ ( 0 to 5 wt pet).

Calcium ions also promote the reaction. The appearance of silicate in Figure 4 indicates that calcium ions entered the silicate and replaced the bonded magnesium to be free ions. Then, $\mathrm{Ca}^{2+}$ combined the silicate and magnesium ions to form a series of new phases, including olivine, monticellite, and merwinite successively. The calcium ions most likely participate in the following reactions:

$$
\begin{gathered}
\mathrm{Ca}^{2+}+\mathrm{Mg}_{2} \mathrm{SiO}_{4}=\mathrm{CaMgSiO}_{4}+\mathrm{Mg}^{2+} \\
\mathrm{Ca}^{2+}+2 \mathrm{CaMgSiO}_{4}=\mathrm{Ca}_{3} \mathrm{Mg}\left(\mathrm{SiO}_{4}\right)_{2}+\mathrm{Mg}^{2+} .
\end{gathered}
$$

The process releases free magnesium ions to promote the reduction of magnesia by carbon. The replacement consumes both calcium fluoride and olivine, leading to a decrease of the eutectic in the samples. The form of silicate containing calcium and magnesium means the loss of $\mathrm{CaF}_{2}$ and $\mathrm{MgO}$. But the molar ratio of $\mathrm{Ca}$ to $\mathrm{Mg}$ is 3 in the last stage of merwinite, and the percentage of $\mathrm{MgO}$ trapped is up to 1.3 pct for the sample with 5 pct $\mathrm{CaF}_{2}$, which has little impact on $\mathrm{MgO}$ reaction rate.

\section{Analysis of Loss of Fluorine}

Finally, the reason for the fluorine loss is discussed. The fluorine loss is proven by XRF (Figure 5); however, there are no new phases containing fluorine in the residue with decreasing $\mathrm{CaF}_{2}$. This finding indicates that fluorine ions should form some type of gaseous fluoride and be expelled with magnesium vapor and carbon monoxide.

According to Eqs. [5] and [6], magnesium fluoride is generated when fluorine ions destroy the magnesia structure. However, it is volatile under the condition of high temperature and vacuum. Thermodynamic analysis confirms that molten magnesium fluoride evaporation begins at $1556 \mathrm{~K}\left(1283{ }^{\circ} \mathrm{C}\right)$ under a vacuum of $10 \mathrm{~Pa}$ and at $1602 \mathrm{~K}\left(1329^{\circ} \mathrm{C}\right)$ at $20 \mathrm{~Pa}$ :

$$
\mathrm{MgF}_{2(1)}=\mathrm{MgF}_{2(\mathrm{~g})} \text {. }
$$

The evaporating temperature is close to $1573 \mathrm{~K}$ $\left(1300{ }^{\circ} \mathrm{C}\right)$ and is lower than $1673 \mathrm{~K}\left(1400{ }^{\circ} \mathrm{C}\right)$, which corresponds to the increase of the magnesia reaction rate. At $1573 \mathrm{~K}\left(1300{ }^{\circ} \mathrm{C}\right)$, magnesium fluoride is generated, thereby accelerating the reaction; however, it evaporates at a relatively low speed. This finding might be the reason that the magnesia reaction rates of RS1, RS3, and RS5 are similar at $1573 \mathrm{~K}\left(1300{ }^{\circ} \mathrm{C}\right)$. From $1573 \mathrm{~K}$ to $1673 \mathrm{~K}$ $\left(1300{ }^{\circ} \mathrm{C}\right.$ to $\left.1400{ }^{\circ} \mathrm{C}\right)$, it evaporates faster. RS1, RS3, and RS5 lose fluorine faster, which leads to reaction rates 
arranged in the order of the $\mathrm{CaF}_{2}$ weight percentage at $1673 \mathrm{~K}\left(1400{ }^{\circ} \mathrm{C}\right)$. At $1673 \mathrm{~K}\left(1400{ }^{\circ} \mathrm{C}\right)$, a great loss of fluorine has occurred. The reaction rates increases slowly.

The generation of magnesium fluoride was confirmed by Wang. ${ }^{24]} \mathrm{MgF}_{2}$ appears in the crystallizer during aluminothermic reduction of dolomite and magnesite with 3 wt pet $\mathrm{CaF}_{2}$ at $1473 \mathrm{~K}\left(1200{ }^{\circ} \mathrm{C}\right)$ under a vacuum of $2 \mathrm{~Pa}$.

In addition to the evaporation of magnesium fluoride, the gasification of silicon tetrafluoride is another possible reason leading to the loss of fluorine. The XRF results (Figure 5) show the clear loss of silicon at any temperature, especially at $1673 \mathrm{~K}\left(1400{ }^{\circ} \mathrm{C}\right)$. Silicon tetrafluoride easily evaporates or sublimates according to thermodynamic analysis. Viswanathan ${ }^{[25]}$ noted that fluoride in a slag system volatized at $1773 \mathrm{~K}\left(1500{ }^{\circ} \mathrm{C}\right)$ and generated $\mathrm{SiF}_{4}, \mathrm{HF}$, and $\mathrm{CaF}_{2}$ as gas and dust. Persson $^{[26}$ studied the fluoride evaporation in three binary $\mathrm{MgO}^{-\mathrm{SiO}_{2}}$ systems containing 3 to $10 \mathrm{wt}$ pct $\mathrm{CaF}_{2}$ and noted that fluorine ions enter into the silicate network and $\mathrm{SiF}_{4}$ gas escapes from the molten surface above $1673 \mathrm{~K}\left(1400{ }^{\circ} \mathrm{C}\right)$.

Certainly, aluminum fluoride gas and calcium fluoride gas may be generated simultaneously, ${ }^{[27,28]}$; however, their effects are less pronounced than those of $\mathrm{MgF}_{2}$ and $\mathrm{SiF}_{4}$. The significant loss of fluorine results in the slowdown of reaction rate.

\section{CONCLUSIONS}

The objective of the work presented here was to determine the acceleration mechanism of calcium fluoride on the vacuum carbothermic reduction of magnesia. Based on the results obtained, the following conclusions can be drawn.

Calcium fluoride and olivine form the eutectic, which forms a channel to aid the solid-solid reaction between carbon and magnesia and facilitates the work of fluorine ions. Fluorine ions are regarded as the critical factor in the acceleration reaction. These ions enter the magnesia crystal lattices through the melt, making them distorted. The structural strength and chemical stability of the magnesia crystal lattice decrease, which facilitates the reduction reaction between carbon and magnesia. Calcium ions replace magnesium ions to form silicate. The gasification of magnesium fluoride and silicon tetrafluoride leads to the loss of fluorine in the samples.

The addition of calcium fluoride promotes the vacuum carbothermal reduction of magnesia. However, the fluoride in the atmosphere results in serious pollution and a series of environmental problems. Maintaining the reduction temperature at approximately $1573 \mathrm{~K}$ $\left(1300{ }^{\circ} \mathrm{C}\right)$ could reduce the evaporation of fluoride and keep the reaction relatively faster.

\section{ACKNOWLEDGMENTS}

The authors gratefully acknowledge "the Fundamental Research Funds for the Central Universities,"
2652015195 and 2652015105 , for the financial support provided for the realization of this work.

\section{OPEN ACCESS}

This article is distributed under the terms of the Creative Commons Attribution 4.0 International Li- cense (http://creativecommons.org/licenses/by/4.0/), which permits unrestricted use, distribution, and reproduction in any medium, provided you give appropriate credit to the original author(s) and the source, provide a link to the Creative Commons license, and indicate if changes were made.

\section{REFERENCES}

1. M. Pourabdoli, S. Raygan, H. Abdizadeh, and K. Hanaei: Rare Met. Mater. Eng., 2006, vol. 35, pp. 74-77.

2. L.Z. Xiong, Q.Y. Chen, Z.L. Yin, P.M. Zhang, Z.Y. Ding, and Z.X. Liu: Adv. Mater. Res., 2012, vol. 22, pp. 694-99.

3. S.Y. Zhong, M.F. Jiang, and H.T. Xu: Adv. Mater. Res., 2012, vols. 347-353, pp. 1180-83.

4. X.M. Li, S.J. Wang, J.X. Zhao, Y.R. Cui, and Y.M. Chen: $A d v$. Mater. Res., 2011, vols. 239-242, pp. 1960-63.

5. Y.W. Dong, Z.H. Jiang, Y.L. Cao, A. Yu, and D. Hou: Metall. Mater. Trans. B, 2014, vol. 45B, pp. 1315-24.

6. Q.Y. Liu, L.Y. Wang, K. Zheng, and H.P. Li: Ionics, 2015, vol. 21, pp. 749-53.

7. L.Z. Xiong, Z.Q. He, and Z.X. Liu: Vacuum, 2015, vol. 119, pp. 163-67.

8. H.H. Jung, Y. Chung, and J.H. Park: Metall. Mater. Trans. B, 2015, vol. 46B, pp. 1154-61.

9. S. Ramakrishnan and P. Koltun: Resour. Conserv. Recycl., 2004, vol. 42, pp. 49-64.

10. Y. Jiang, H.W. Ma, and Y.Q. Liu: Light Met., 2013, vol. 03, pp. $40-53$.

11. R.T. Li, P. Wei, and S. Masamichi: Metall. Mater. Trans. B, 2003, vol. 34B, pp. 433-37.

12. Y. Tian, T. Qu, B. Yang, Y.N. Dai, B.Q. Xu, and S. Geng: Metall. Mater. Trans. B, 2012, vol. 43B, pp. 657-61.

13. J.C. Gao, X.H. Chen, and Q.F. Tang: J. Funct. Mater., 2012, vol. 43, pp. 1312-15.

14. H. Mizoguchi, H. Suzuki, and S. Hayashi: ISIJ Int., 2011, vol. 51 (8), pp. $1247-54$.

15. C.H. Huang, C.L. Lin, and H.K. Chen: J. Chin. Inst. Chem. Eng., 2007, vol. 38, pp. 143-49.

16. A.S. Berezhnoi: Dopov. Akad. Nauk Ukr. RSR, 1951, vol. 4, pp. 248-52.

17. Y. Sasaki and M. Iguchi: ISIJ Int., 2009, vol. 49 (4), pp. 602-04.

18. R.D. Shannon: Acta Cryst., 1976, vol. A32, pp. 751-67.

19. B. Mirhadi and B. Mehdikhani: Process. Appl. Ceram., 2012, vol. 6, pp. 159-64.

20. M. Backhaus-Ricoult: Acta Mater., 2001, vol. 49, pp. 1747-58.

21. S. Nasr, E.B. Salem, H. Boughzal, and K. Bouzouita: Ann. Chim. Sci. Mater., 2011, vol. 36, pp. 159-76.

22. S. Nasr, A. Hassine, and K. Bouzouita: J. Biomater. Nanobiotechnol., 2013, vol. 4, pp. 1-11.

23. W. Sheline, L. Matthews, N. Lindeke, S. Duncan, and R. Palumbo: Energy, 2013, vol. 51, pp. 163-70.

24. Y.W. Wang, J. You, N.X. Feng, and W.X. Hu: J. Vac. Sci. Technol., 2012, vol. 32, pp. 889-95.

25. N.N. Viswanathan, S. Fatemeh, D. Sichen, and S. Seetharaman: Steel Res., 1999, vol. 70, pp. 53-58.

26. M. Persson and S. Seetharaman: ISIJ Int., 2007, vol. 47, pp. 1711-17.

27. M.O. Suk and H.J. Park: J. Am. Ceram. Soc., 2009, vol. 92 (3), pp. $717-23$.

28. J.X. Zhao, Y.M. Chen, X.M. Li, Y.R. Cui, and X.T. Lu: J. Iron Steel Res. Int., 2011, vol. 18(10), pp. 24-28, 53. 